Alice Michelas Moreira

A importância da língua materna

Monografia

Departamento de Letras

Pós-graduação lato sensu

Formação de Intérpretes de Conferência

Rio de Janeiro, 26 de junho de 2012 
DEPARTAMENTO DE LETRAS

Pós-graduação lato sensu Formação de Intérpretes de Conferência

\section{A importância da língua materna}

Alice Michelas Moreira Orientadora: Branca Vianna 


\section{Pontifícia Universidade Católica \\ DO RIO DE JANEIRO}

Alice Michelas Moreira

A importância da língua materna

Monografia apresentada ao Programa de Pós-Graduação em Letras da PUC-Rio como requisito parcial para obtenção do diploma do curso de Especialização Formação de Intérprete de Conferências da PUC-Rio. Aprovada pela Comissão Examinadora abaixo assinada.

Orientadora:

Branca Vianna

Rio de Janeiro, 26 de junho de 2012

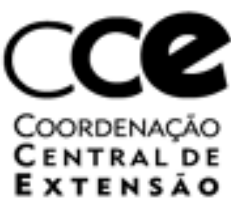




\section{AGRADECIMENTOS}

Aos professores pela dedicação e por me fazerem descobrir a fascinante atividade que é a interpretação.

À professora Branca Vianna pelo trabalho de orientação.

Aos colegas e amigos pelo companheirismo e carinho durante todo o curso.

À minha família pelo apoio em tudo que faço. 


\section{RESUMO}

Este trabalho discute a importância da língua materna para o intérprete de conferências. O objetivo do trabalho é entender melhor o que o termo língua materna significa e a relação com o equivalente na classificação linguística utilizada na área da interpretação: língua A. Através de uma revisão da literatura da área, são expostas diferentes definições de termos relevantes para a classificação linguística. Estabelecemos assim um arcabouço teórico que serve de base para o restante do trabalho, com ênfase nas competências linguísticas necessárias em cada categoria linguística. São também exploradas duas situações peculiares: a do intérprete bilíngue e o que denomina-se indivíduo "sem língua", que devido a um contexto específico se depara com um conhecimento insuficiente em língua materna. O trabalho busca orientar alunos de interpretação na avaliação de suas línguas, tanto no momento de ingresso em um curso de especialização quanto após o término.

Palavras-chave: língua materna, língua A, bilinguismo, intérprete bilíngue, indivíduo sem língua, língua ativa, língua passiva. 


\section{ABSTRACT}

This paper examines the importance of one's mother tongue in conference interpretation. The purpose of this paper is to better understand what the term mother tongue means and its relation to what is commonly used in interpreter language classification: A language. Through an examination of publications in the area, the paper raises different definitions of terms that are relevant to language classification. Thus, it establishes a theoretical framework that serves as the basis for the remainder of the work, with an emphasis on the linguistic competencies required in each language category. It further explores two unique situations: that of the bilingual interpreter, and that of the individual with insufficient knowledge of his mother tongue, what we call an "alingual individual". This paper aims to serve as a guide that will help interpreting students in assessing their languages, both when starting and after having completed an interpreting course.

Key-words: mother tongue, A language, bilingualism, bilingual interpreter, alingual individual, active language, passive language. 


\section{SUMÁRIO}

1. Introdução 6

2. As línguas do intérprete $\quad 9$

2.1 Línguas ativas e passivas 10

$\begin{array}{ll}2.2 \text { Língua A } & 11\end{array}$

2.3 Língua A: competências específicas 13

2.4 Língua B: uma língua verdadeiramente ativa 15

3. Bilinguismo 18

3.1 A visão "monolíngue" ou parcial 19

3.2 A visão "bilíngue" ou global 20

3.3 Tipos de bilinguismo na interpretação 22

$3.4 \mathrm{O}$ intérprete bilíngue 23

4 Indivíduo "sem língua" 25

5 Conclusão $\quad 27$

Referências Bibliográficas $\quad 29$ 


\section{1 \\ INTRODUÇÃO}

Como classificar as diferentes línguas de trabalho do intérprete? Essas línguas são definidas pela AIIC, Associação Internacional de Intérpretes de Conferências, como as línguas que o intérprete usa profissionalmente. ${ }^{1} A$ tarefa de classificá-las é uma questão com a qual o intérprete se depara em vários momentos de sua vida. Num primeiro momento, ao ingressar num curso de especialização. No final deste, o intérprete também deve avaliar as suas línguas de trabalho. Essa tarefa é de extrema importância, pois permite ao intérprete aceder ao mercado profissional com a segurança de que essa classificação será compreendida por todos da mesma maneira. No entanto, há casos em que esse processo pode não ser tão simples.

Muitos se interessam pela profissão por preencherem uma das muitas exigências necessárias antes de empreender qualquer formação na área: o domínio de uma ou mais línguas estrangeiras. Tal domínio é testado durante um processo de seleção que é conduzido pela maioria dos cursos de formação e que busca detectar no indivíduo, através de um processo de entrevista e provas escrita e/ou oral, as características de todo bom intérprete: conhecimento dos idiomas estrangeiros, cultura das línguas, cultura geral, agilidade mental, segurança, e finalmente, um excelente domínio de sua língua materna.

Aida González Del Álamo, intérprete de conferência profissional e professora do EstudioSampere de Madrid, mantém um blog no qual relata uma experiência reveladora. $\mathrm{Na}$ tentativa de explicar por que tantos candidatos são reprovados nos exames de seleção de intérpretes da ONU, Aida afirma que o principal problema estaria na língua materna, já que na sede das Nações Unidas, é geralmente para esta que o intérprete traduz. Portanto, se um candidato demonstra ter problemas com a língua materna, suas chances diminuem. De acordo com a autora, os fatores

\footnotetext{
${ }^{1}$ http://aiic.net/ViewPage.cfm/article1097, acesso em 11/05/2012
} 
que levavam à reprovação do candidato estavam mais frequentemente relacionados à incapacidade de escrever bem na língua materna ou vocabulário insuficiente. ${ }^{2}$

Este trabalho tratará da importância da língua materna para o intérprete de conferências, abordando também situações fora do comum, como por exemplo, a do intérprete bilíngue, ou do aspirante a intérprete que, devido a um contexto específico, depara-se com um conhecimento insuficiente de sua língua materna.

O primeiro capítulo buscará definir o termo "língua materna" e relacioná-lo ao que é comumente utilizado na classificação linguística adotada internacionalmente pelos intérpretes de conferência profissionais: o termo "língua A". Os principais autores citados neste capítulo fazem parte da bibliografia do curso de formação de Intérpretes de Conferência da PUC, bem como de cursos de interpretação no mundo todo. Estão entre alguns dos mais renomados autores da área e incluem Daniel Gile (2009), ValerieTaylor-Bouladon (2007) e Roderick Jones (2002), entre outros. As principais definições encontradas serão expostas, ressaltando erros de concepção comuns, assim como termos relacionados que servirão de base para o restante do trabalho.

O segundo capítulo tratará da primeira situação extraordinária pesquisada: a do intérprete bilíngue. Embora o bilinguismo seja uma noção extremamente ampla e que pode ser estudada sob vários pontos de vista (linguístico, psicológico, sociológico, entre outros), o interesse aqui será a sua relação com a interpretação. Serão explicitadas as principais teorias estudadas para tentar explicar esse fenômeno, passando pelo trabalho de autores como François Grosjean (1982) e Cristopher Thiéry (1978), entre outros. Finalmente, analisaremos a manifestação e efeito desse fenômeno no intérprete.

O terceiro e último capítulo abordará a última situação singular observada: a do indivíduo "sem língua A". Para esse indivíduo, o conhecimento que detém na língua materna é insuficiente para que esta possa ser usada como língua de trabalho. A ênfase será no contexto que dá origem a esse tipo de situação, que

${ }^{2}$ http://aidagda.com/2011/05/04/i-conferencia-mou-parte-1-con-la-lengua-materna-hemos-topado/, acesso em 10/02/2012 
muitas vezes, só é detectada em aspirantes a intérprete, dado que em outro contexto, tal conhecimento da língua e de sua cultura pode ser adequado.

O objetivo é elucidar o que realmente entendemos quando usamos tais termos, ressaltando também as exigências implícitas por trás da classificação linguística. Este trabalho visa orientar alunos de interpretação, tanto no momento do ingresso no curso de especialização quanto na avaliação após o término da formação. Finalmente, o trabalho trará um enfoque especial sobre a questão da língua materna, muitas vezes negligenciada devido à atenção prestada às demais línguas de trabalho (as línguas estrangeiras). 


\section{2 \\ AS LÍNGUAS DO INTÉRPRETE}

As línguas, principal instrumento de trabalho do intérprete, são de suma importância para a tarefa de interpretação. Tanto o conhecimento já adquirido em uma língua, seja ele linguístico ou cultural, quanto a sua manutenção e constante evolução fazem parte do trabalho diário de um intérprete de conferência.

Durante o ato de interpretação, o esforço cognitivo exige do intérprete um malabarismo mental; conforme ouve sons, os processa e armazena as informações por um tempo curto, deve também produzir uma versão em outro idioma. A esses esforços é somada uma série de fatores agravantes como ansiedade, estresse, tensão física e mental, entre outros. Esses podem ser vistos em menor ou maior grau dependendo da experiência do intérprete e da sua familiaridade com os termos técnicos -fruto de uma boa preparação. Fatores fora do seu controle, como um palestrante muito rápido, falhas no som e distrações, também podem ter influência negativa sobre o seu rendimento.

Dada a situação de "gestão de crise" (minha tradução, GILE, 2009, p. 191) ${ }^{3}$ em que o intérprete se encontra, o domínio da língua para a qual traduz é condição fundamental para boa interpretação. $O$ intérprete deve ter em mente o conhecimento linguístico e extralinguístico que possui para cada uma de suas línguas de trabalho. Consequentemente, deve ser bastante cauteloso ao classificálas. Para todas as línguas com as quais trabalha, seja de maneira ativa ${ }^{4}$ ou passiva $^{5}$, é necessário possuir e cultivar um conhecimento geral em áreas como economia, história, direito, política internacional, entre outras. Ao mesmo tempo é importante que se mantenha atualizado quanto às principais notícias, lendo jornais em cada uma de suas línguas de trabalho regularmente.

\footnotetext{
3 "Interpreting has been referred to by some professionals as (permanent) crisis management [...]"

${ }^{4}$ Língua ativa: língua(s) para a(s) qual(is) o intérprete é capaz de interpretar profissionalmente.

${ }^{5}$ Língua passiva: língua(s) a partir da(s) qual(is) o intérprete é capaz de interpretar profissionalmente.
} 
Como saber, portanto, se o conhecimento linguístico que possui em uma determinada língua é suficiente ou não para exercer tal atividade profissionalmente? É o que buscaremos abordar ao longo desse capítulo, através de diferentes definições de termos centrais para a classificação linguística que foram levantadas durante uma pesquisa do material publicado pelos principais teóricos da área.

\section{1}

\section{Línguas ativas e passivas}

A classificação linguística faz uma distinção importante entre língua ativa e língua passiva. Mas por que essa distinção existe e o que significa?

Conforme anteriormente definido, a diferença entre língua ativa e língua passiva está no uso. Línguas ativas, que são as que o intérprete fala, exigem um domínio muito maior da capacidade de produção. As línguas passivas, por outro lado, são as línguas que o intérprete ouve. Para esse tipo de língua, o intérprete também deve ter um bom conhecimento geral mas a habilidade que the será mais exigida é a de compreensão.

A diferença entre esses dois tipos de classificação se justifica por um motivo principal: a língua ativa é a que o público ouve e portanto a língua através da qual o intérprete será avaliado. Para Jean Herbert (1952), "o intérprete tem a obrigação de ser uma autoridade na língua que fala" (minha tradução, HERBERT, 1953, p.64). ${ }^{6}$ Herbert alerta para o que pode acontecer com o intérprete ao trabalhar para uma língua em que não possui domínio suficiente: "se ele usa uma língua que não domina plenamente, cometerá um número muito maior de erros que no uso diferente desta mesma língua, pois sua atenção está voltada para outras questões" (minha tradução, HERBERT, 1952, p.64). ${ }^{7}$

O domínio insuficiente que Herbert menciona pode provocar falhas na interpretação como, por exemplo, interferências. Interferências linguísticas podem

\footnotetext{
6 "The interpreter is under an obligation to be an authority on the language he speaks".

7 "If he uses a language which he has not fully mastered, he will make far more mistakes than he would in a different use of the same language, because all his attention is occupied elsewhere".
} 
levar o intérprete a "utilizar uma palavra de forma incorreta em relação ao sentido ou conotação, distorcer sua pronúncia na fala ou sua grafia na escrita, ou até mesmo usar palavras da língua errada no meio de um discurso ou texto" (minha tradução, GILE, 2009, p.231). ${ }^{8}$ Esse tipo de falha deve ser evitada ao máximo, o que justifica precaução por parte do intérprete quando estiver incerto sobre a condição ativa de uma língua de trabalho. Vale lembrar a advertência feita por Taylor-Bouladon (2007): "Quando chegar a hora de buscar uma certificação como intérprete de conferência profissional, seja modesto" (minha tradução, TAYLOR-BOULADON, 2007, p. 152). ${ }^{9}$

Enquanto que as línguas passivas são sempre denominadas língua $C$, as línguas ativas são subdivididas em dois tipos: língua $A$ e língua $B$. Definiremos a língua A na próxima seção.

\section{2}

\section{Língua A}

A AllC, Associação Internacional de Intérpretes de Conferências, fornece em seu site a seguinte definição:

Língua $\mathrm{A}$ - A língua nativa do intérprete (ou outra língua estritamente equivalente à língua nativa), para a qual o intérprete trabalha a partir de todas as suas demais línguas nas duas modalidades de interpretação, simultânea e consecutiva (minha tradução). ${ }^{10}$

Essa definição parece ser a mais comum e variantes foram encontradas também em publicações de importantes autores de teoria da interpretação de conferência (TAYLOR-BOULADON, 2007; GILE, 2009). Tal definição está calcada numa noção que não é explicitamente esclarecida: a de língua nativa. O dicionário Aurélio sugere a seguinte definição: "língua que identifica o indivíduo com uma cultura ou comunidade e que geralmente coincide com a língua materna" (FERREIRA, 1999).

\footnotetext{
8 "Linguistic interference can cause the interpreter or translator to use a word incorrectly with respect to its meaning or connotation, to distort its sound when speaking or spelling when writing, or even to use a word from the wrong language in the middle of a speech or text".

9 "When the time comes to seek accreditation as a professional conference interpreter, be modest".

${ }^{10}$ http://aiic.net/glossary/default.cfm?ID=9\&letter=A, acesso em 15/02/2012.
} 
Esta questão é mencionada por ValerieTaylor-Bouladon (2007), importante contribuinte para a área da interpretação cujo livro Conference Interpreting: Principles and Practice é uma referência completa para todo aluno de interpretação ou intérprete profissional. No livro, Taylor-Bouladon (2007) devota um capítulo inteiro à questão da língua materna ("What conference interpreters do: Mother tongue and the brain"). Ela cita o Professor Tadanobu Tsunoda, que após uma série de estudos sobre lateralidade e dominância cerebral concluiu "que a língua materna adquirida na infância está fortemente relacionada à formação da cultura e mentalidade singulares de cada grupo étnico" (TAYLOR-BOULADON, 2007, p.57). A primeira característica de uma língua $A$ é, portanto, que ela está vinculada a uma cultura da qual o intérprete participa e que entende profundamente.

O momento do aprendizado parece ser outro fator determinante na possibilidade de uma língua ser qualificada de materna ou não. De acordo com Thierry Opillard (2006), certas características físicas estão diretamente relacionadas à forma de aquisição de uma língua:

"Pesquisadores do bilinguismo concordam que existe um período crítico além do qual a aquisição de uma outra língua muda de natureza. Entre os três e cinco primeiros anos de vida, a plasticidade do cérebro possibilita uma fixação das competências linguísticas que coloca os elementos da comunicação à disposição do falante de maneira espontânea; a gramática é internalizada, o vocabulário está disponível sem esforço. Então, esta plasticidade diminui até cerca dos 12 anos quando o falante vai recorrer cada vez mais a processos conscientes, voluntários, explícitos, como fazem adultos que iniciam o estudo de uma língua estrangeira" (minha tradução, OPILLARD, 2006, p.80). ${ }^{11}$

Esse tipo de aprendizado também é chamado de aquisição por imersão. Cristopher Thiéry (1978), teórico na área de bilinguismo e interpretação, considera que a língua materna é "a língua (ou línguas) que uma criança adquiriu por 'imersão', i.e., através da reação natural aos sons produzidos no seu ambiente a fim de comunicar-se com este" (minha tradução, THIERY, 1978, p. 146) ${ }^{12}$. Portanto,

\footnotetext{
11 “Les 'chercheurs en bilinguisme' s'accordent à dire qu'il y a une période critique au-delà de laquelle l'acquisition d'une autre langue change de nature. Dans les trois à cinq premières années de la vie, la plasticité du cerveau permet une fixation des compétences linguistiques qui mettront à la disposition du locuteur les éléments de la communication de façon spontanée la grammaire est internalisée, le vocabulaire est disponible sans effort. Ensuite, cette plasticité diminue jusqu'à environ l'âge de douze ans où alors le locuteur va faire appel de plus en plus à des procédures conscientes, comme le font les adultes qui se mettent à l'étude d'une langue étrangère".

12 "[...] the language (or languages) which the child has acquired by 'immersion', i.e., by natural reaction to the sounds made by its environment in order to communicate with it".
} 
outra característica importante da língua materna é o fato de o aprendizado não ser mediado por nenhuma outra língua.

No entanto, é interessante observar que as definições acima não fazem nenhuma menção ao nível de fluência e conhecimento necessários para qualificar uma língua como materna. Em seu livro Conference Interpreting Explained, Roderick Jones (2002) é um dos únicos teóricos explorados neste trabalho a explicitar que a língua materna não precisa estar relacionada aos pais ou até mesmo ao país de origem, definindo-a como a "melhor língua ativa do intérprete" (JONES, 2002, p. 131). Aqui, Jones (2002) escolhe uma abordagem em que a definição passa por uma avaliação qualitativa. Jones (2002) usa o termo língua materna para se referir à primeira e melhor língua ativa do intérprete, o que equivale à língua $\mathrm{A}$.

Por ser a melhor língua ativa, certas competências se aplicam exclusivamente ao domínio em língua $\mathrm{A}^{13}$. Abordaremos estas competências na próxima seção.

\section{3}

\section{Língua A: competências específicas}

Em seu trabalho sobre o aperfeiçoamento linguístico para os intérpretes que trabalham para língua B (Le perfectionnement linguistique pour les interprètes vers la langue B), Malgorzata Tyruk (2002) relembra brevemente as cinco competências necessárias em língua $A$. Estas competências foram idealizadas e denominadas “inteligência verbal” por John B. Carroll(1978), psicólogo americano reconhecido por ter desenvolvido trabalho seminal na área de linguística aplicada.

A primeira competência é a competência lexical. É definida como a "capacidade de reconhecer e utilizar palavras de uma língua da mesma forma que

\footnotetext{
${ }^{13}$ Os termos língua A e língua materna serão utilizados como sinônimos daqui pra frente.
} 
os falantes daquela língua" (minha tradução). ${ }^{14}$ Por exemplo, falantes de um idioma devem ser capazes de reconhecer uma palavra como cadeira e saber diferenciá-la de outras palavras associadas como banco, sofá, poltrona. Também devem saber que uma cadeira é um tipo de móvel e que existem vários tipos de cadeiras: cadeira de escritório, cadeira de rodas, cadeira de praia, etc. Finalmente, devem ser capazes de entender que a palavra cadeira no plural (cadeiras) em certos contextos pode ser utilizada para se referir ao quadril de uma mulher.

A segunda competência é a "sensibilidade a certos usos do léxico e a nuances de expressões idiomáticas" (minha tradução, TYRUK, 2002, p.51). Essa competência inclui saber identificar nuances nos significados entre sinônimos, como medo, pavor, terror, receio. Inclui também a compreensão e uso apropriado de expressões idiomáticas. Tal capacidade permite que o intérprete escolha a palavra mais adequada ou uma expressão idiomática que traduza o sentido original em uma fração de segundo.

A terceira competência mencionada é a "capacidade de prever combinações lexicais num enunciado" (minha tradução, TYRUK, 2002, p.51). As combinações lexicais são sequências de palavras que ocorrem naturalmente no discurso. A colocação, por exemplo, é um tipo de combinação lexical definida como "um par ou grupo de palavras que são normalmente justapostas" (minha tradução). ${ }^{15}$ Tais colocações podem se referir à combinação de diversos tipos de palavras: nominal ("cartão de crédito"); adjetiva ("cinema mudo", "fumante inveterado"); verbal ("tomar uma decisão", "prestar atenção"); adverbial (“acreditar piamente”, "pedir encarecidamente"). Essa competência é extremamente importante para o intérprete; em alguns casos, devido a uma falha no som ou pronúncia do orador o intérprete pode ter ouvido apenas parte do enunciado e deduzir aquilo que ficou incompreensível.

A quarta e penúltima competência é o que Tyruk (2002) chama de "reconhecimento de ambiguidades semânticas e sintáticas" (minha tradução, TYRUK, 2002, p.51). A ambiguidade semântica "ocorre quando há mais de uma

\footnotetext{
${ }^{14}$ http://www.sil.org/lingualinks/languagelearning/otherresources/gudlnsfralnggandcltrlrnngprgrm/Whatls LexicalCompetence.htm, acesso em 01/05/2012

${ }^{15}$ http://oxforddictionaries.com/definition/collocation?region=us\&q=collocation, acesso em 02/05/2012
} 
interpretação possível para o relacionamento dos termos na frase" (BRÄSCHER, 2002, p. 4). Por exemplo, na frase: “João está no banco", há duas opções de significado segundo a interpretação. Ou João está numa instituição financeira, ou ele está sentado num banco. Por outro lado, a ambiguidade sintática "ocorre na estruturação da frase em constituintes hierarquizados, quando se definem as ligações que estabelecem os sintagmas" (BRÄSCHER, 2002, p. 4). Na seguinte frase, observarmos uma ambiguidade sintática porque resulta do modo como as palavras são encadeadas: "Eu li a notícia sobre a greve na universidade". Eu posso ter lido a notícia enquanto estava na universidade, ou então a greve está acontecendo na universidade. Para o intérprete, a capacidade de reconhecer esses diferentes tipos de ambiguidades é essencial. Em alguns casos, tal ambiguidade pode fazer parte da intenção original do orador - comum no caso de piadas - e cabe ao intérprete processar a informação rapidamente e buscar algum equivalente na língua alvo. ${ }^{16} \mathrm{Em}$ outros, o intérprete deve estar suficientemente inserido no contexto para interpretar tal ambiguidade apropriadamente.

Finalmente, a última competência é a capacidade de se expressar de maneira eficaz (TYRUK, 2002, p.51). Essa competência é ainda mais crucial para o intérprete, que deve sempre buscar a reformulação mais eficaz. O intérprete está constantemente sob pressão em relação ao tempo, tendo que produzir uma fala num ritmo que lhe é ditado pelo orador. É necessário ter versatilidade para ser capaz de escolher, entre as diferentes opções e numa fração de segundo, a forma mais eficaz de transmitir a mensagem do orador. De acordo com Jones (2002), cada segundo conta e o intérprete deve até mesmo optar pela reformulação que contiver o menor número de sílabas. Vale ter em mente que alguns idiomas, como o inglês, são naturalmente mais densos e sucintos. Uma interpretação de língua inglesa para uma língua latina, como o português, pode forçar o intérprete a usar até cinquenta por cento mais palavras (JONES, 2002, p. 95).

\section{4}

\section{Língua B}

A língua B é definida pela AllC da seguinte forma:

\footnotetext{
${ }^{16}$ A língua alvo é a língua para a qual traduz.
} 
"Língua B - Uma língua outra que a língua nativa, em que o intérprete possui um domínio perfeito e para a qual traduz a partir de uma ou mais línguas. Alguns intérpretes traduzem para a língua "B" em apenas uma das duas modalidades de interpretação" (minha tradução). ${ }^{17}$

Há nesta definição uma certa ambiguidade em relação à característica ativa da língua $B$. De acordo com a definição, o fato de usar a língua $B$ de forma ativa não é regra já que alguns intérpretes só o fazem em certas condições (uma das duas modalidades). Gile (2009) usa essa mesma definição como base no capítulo 9 do livro previamente mencionado, ressaltando que o verdadeiro status das línguas de trabalho é menos claro na prática, onde observamos esse mesmo tipo de ambiguidade em relação à qualidade ativa da língua $B$ dependendo do contexto.

Durante muitos anos, houve uma forte defesa do uso exclusivo da língua $A$ por expoentes e professores de interpretação importantes como Danica Seleskovitch (1968), que viria a fundar o centro de interpretação da École Supérieure d'Interprètes et de Traducteurs (ESIT), da Universidade de Paris III. A partir de observações pessoais em várias conferências, Seleskovitch conclui que "é possível afirmar que se compararmos dois intérpretes de nível equivalente, a interpretação para língua $A$ - língua materna - é sempre superior à interpretação para língua B - língua adquirida" (minha tradução, citada por MINNS, 2002, p.35). ${ }^{18}$

Em alguns contextos, o uso das línguas obedece à definição acima e a língua B costuma ser usada de maneira ativa apenas em consecutiva. Nessa modalidade, o intérprete está sentado na mesa de conferência próximo ao orador, ouve um discurso, toma notas e posteriormente relata o que foi dito em outra língua a partir das anotações. ${ }^{19}$ A reformulação é feita a partir de algumas palavras chave que foram anotadas pelo intérprete para servirem de gatilho e auxiliá-lo na recuperação da mensagem original. Consequentemente, há um distanciamento maior da fala original e a interferência da forma de uma língua sobre a outra é reduzida. Esse tipo de uso da língua B parece ser a prática mais disseminada no mercado institucional europeu, onde adotou-se um sistema de cabines em que os intérpretes normalmente traduzem para a língua materna a partir de uma série de outras

\footnotetext{
${ }^{17}$ http://aiic.net/glossary/default.cfm?ID=49\&letter=B, acesso em 15/02/2012.

${ }_{18}$ On peut affirmer qu'à qualité égale d'interprète, l'interprétation en $\mathrm{A}$ (langue maternelle) est toujours supérieure à l'interprétation en $B$ (langue acquise).

${ }^{19}$ http://aiic.net/ViewPage.cfm/article1097, acesso em 18/05/2012
} 
línguas passivas. No entanto, até mesmo dentro da tradição do mercado institucional, essa tendência vem sendo posta à prova nos últimos anos: "Há uma tendência geral de interpretar simultaneamente para a língua B a partir de idiomas de uso menos disseminado no ambiente institucional [...]" (minha tradução, DONOVAN, 2002, p. 2). ${ }^{20}$

Fora desse mercado, é frequentemente impossível conseguir montar cabines de interpretação de forma que todos possam falar unicamente a língua materna: "Interpretar para a língua B é considerado indispensável nesse mercado [mercados privados do Leste Europeu], visto que intérpretes com a língua materna apropriada não estão necessariamente sempre disponíveis e consequentemente, os clientes acabam não tendo outra opção" (minha tradução, SZABARI, 2002, p. 13). ${ }^{21}$ Essa parece ser a situação predominante em mercados privados - principalmente fora da Europa Ocidental - e em países onde há uma quantidade menor de intérpretes e uma combinação linguística menos diversa.

Com a entrada de um número maior de países na União Europeia, este argumento tende a ser posto à prova. "A importância de traduzir para a língua $B$ aumentará na União Europeia com a sua expansão" (SZABARI, 2002, p. 17). A crescente globalização acompanha esse movimento; tornou-se cada vez mais comum falar mais de um idioma desde a infância, o que leva a um número maior de indivíduos bilíngues. Mas como definir o bilinguismo e qual é o efeito dessa tendência para o intérprete?

\footnotetext{
20 "There is a general trend towards SI into B from the less widely used languages in the institutional setting and towards bilingual markets with systematic SI back into B on private markets."

21 "Working into the $B$ language is deemed indispensable in this market [WESTERN EUROPEAN FREE MARKETS] as interpreters with the appropriate mother tongue are not necessarily available at all times and clients therefore do not have a choice."
} 


\section{BILINGUISMO}

A maioria das pessoas ainda acredita que o bilinguismo é um fenômeno pouco disseminado que se limita a países com mais de uma língua oficial, como o Canadá ou a Suíça. No entanto, de acordo com François Grosjean (1982), importante teórico que já publicou uma variedade de livros e artigos sobre o tema, "o bilinguismo está presente em praticamente todos os países do mundo, em todas as classes da sociedade e em todas as faixas etárias" (minha tradução, GROSJEAN, 1982, p.1). ${ }^{22}$ Consequentemente, o bilinguismo também está presente em países supostamente monolíngues, como o Brasil.

Se consultarmos o dicionário, a questão pode parecer relativamente simples. De acordo com o dicionário Oxford, o adjetivo "bilíngue" é definido como "pessoa que fala duas línguas fluentemente" e também, quando se referir a país, cidade ou comunidade, "que usa duas línguas, especialmente oficialmente". ${ }^{23}$ Estas definições parecem bastante próximas da visão popular. Na prática, no entanto, o conceito de bilinguismo tem recebido atenção acadêmica importante desde o início do século.

Leonard Bloomfield (1984), linguista americano que em 1933 publicou a obra seminal Language, está entre os primeiros pesquisadores a pesquisar a noção de bilinguismo. Vários pesquisadores desenvolveram teorias na mesma linha que Bloomfield, entre eles Chrisopher Thiéry (1978), enquanto outros rotularam sua visão de parcial. Com o tempo, a questão foi sendo estudada sob perspectivas diferentes e adquiriu maior complexidade.

Ao longo deste capítulo, abordaremos essas diferentes visões buscando explicitar em que pontos elas divergem. As teorias serão então aplicadas à situação peculiar do intérprete. Será que todo intérprete é bilíngue? Quais são as características de um intérprete bilíngue?

\footnotetext{
22 "Bilingualism is present in practically every country of the world, in all classes of society, and in all age groups".

${ }^{23}$ http://oxforddictionaries.com/definition/bilingual?region=us\&q=bilingualism\#bilingual 5 , acesso em 09/04/2012
} 
3.1

Visão "monolíngue" ou parcial

A visão teorizada por Bloomfield (1984) defende a ideia de que o verdadeiro bilíngue deve ter um controle de dois idiomas equivalente ao de um nativo: "nos casos em que este aprendizado perfeito do idioma estrangeiro não leva a uma perda da língua nativa, o resultado é o bilinguismo, o controle nativo de duas línguas" (minha tradução, BLOOMFIELD, 1984, p. 56). ${ }^{24}$

Cristopher Thiéry (1978) usa uma formulação diferente para expressar a mesma noção: "um verdadeiro bilíngue é alguém tido como igual por membros de duas comunidades linguísticas diferentes, aproximadamente no mesmo nível social e cultural" (minha tradução, citado por MARCELINO, 2009, p. 3) ${ }^{25} \mathrm{Em}$ outro artigo, Thiéry (1999) ressalta ainda a diferença no processo de aquisição: por um lado, línguas adquiridas por imersão e por outro, línguas adquiridas a partir de uma língua materna. O autor acrescenta ainda que:

No primeiro caso, a criança (já que essa habilidade parece desaparecer antes da idade adulta) literalmente aprende a falar uma segunda ou terceira vez, através do processo natural e inconsciente de aquisição da língua, ficando com várias "línguas maternas", que podem coexistir ou não, dependendo das circunstâncias (minha tradução, THIÉRY, 1999, p. 4). ${ }^{26}$

Esta teoria serviu de base para vários estudos sobre o bilinguismo, mas também se assimila à noção popular de quem é ou não bilíngue. Conforme Marcello Marcelino (2009) ressalta, a maioria dos indivíduos acredita que é necessário crescer falando duas línguas ou ser falante nativo de duas línguas para ser considerado bilíngue (MARCELINO, 2009, p.3).

François Grosjean (2008), co-fundador da revista científica Bilingualism: Language and Cognition, é tido como um dos principais contribuintes da área. Grosjean (2008) é contrário a essa visão por acreditar que exclui a maior parte dos

\footnotetext{
24 "In the cases where this perfect foreign-language learning is not accompanied by loss of the native language, it results in bilingualism, the native-like control of two languages."

25 "A true bilingual is someone who is taken to be one of themselves by the members of two different linguistic communities, at roughly the same social and cultural level."

26 "In the first case the child (because the ability seems to disappear before adulthood) literally learns to speak a second or third time, by the natural unconscious process of language acquisition, ending up with several 'mother tongues' that may or may not coexist, depending on circumstances".
} 
falantes de dois idiomas que não possuem nível de fluência nativo, nem conseguem se fazer passar por membros de duas culturas diferentes. Para Grosjean (2008), o "bilíngue não é a soma de dois monolíngues completos ou incompletos; pelo contrário, possui uma configuração linguística singular e específica" (minha tradução, GROSJEAN, 2008, p. 10) ${ }^{27}$. Foi ele quem classificou tal visão de "monolíngue" ou parcial e por oposição, criou uma nova definição de bilinguismo que denomina visão "bilíngue" ou global.

\section{2}

Visão "bilíngue" ou global

No livro Studying Bilinguals, Grosjean (2008) faz uso de uma analogia muito clara para defender sua posição no debate em torno do verdadeiro bilinguismo. $O$ autor faz uma comparação entre o intérprete e o corredor de obstáculos. A tarefa do corredor de obstáculos exige o domínio de dois tipos de competência: salto e corrida. Quando comparado individualmente aos atletas de corrida de velocidade ou salto em altura, a sua competência está aquém do nível desses dois atletas. No entanto, o corredor de obstáculos precisa ser avaliado dentro do seu próprio contexto, onde é um legítimo atleta cuja competência é de natureza diferente (GROSJEAN, 2008). O mesmo vale para o bilíngue que, na sua opinião, não deve ser comparado ao falante nativo de cada idioma.

De acordo com Grosjean (1994), são considerados bilíngues "aqueles que utilizam duas (ou mais) línguas (ou dialetos) no dia a dia" (GROSJEAN, 1994, p.1). Aqui, não há nenhuma referência ao nível de fluência necessário, estabelecendo-se um único critério: o uso diário da língua. Grosjean (1994) defende essa teoria por acreditar que é a mais inclusiva. No entanto, de acordo com essa classificação, não há nenhuma forma de diferenciar um bilíngue de fluência nativa de uma pessoa que utilize o idioma de maneira mais primitiva, o que o autor vê como um ponto positivo: "nossa definição inclui pessoas que vão do trabalhador imigrante, que fala com certa dificuldade na língua do país onde reside (e não sabe nem ler nem escrever) até o

\footnotetext{
27 "The bilingual is not the sum of two complete or incomplete monolinguals; rather, he or she has a unique and specific linguistic configuration".
} 
intérprete profissional que é totalmente fluente em duas línguas" (GROSJEAN, 1994 , p.1). ${ }^{28}$

Há uma série de definições por outros contribuintes importantes que parecem ter influenciado a visão inclusiva de Grosjean (1982). Haugen (1969), por exemplo, propôs uma teoria onde o nível de fluência é organizado em um continuum:

O bilinguismo pode ter todos os níveis de realização, mas entendemos aqui que iniciase no momento em que o falante de uma língua é capaz de produzir enunciados completos e significativos em outra língua. A partir daí, passa por todas as gradações possíveis até chegar ao tipo de habilidade que permite que uma pessoa passe por nativa em mais de um ambiente linguístico (HAUGEN citado por GROSJEAN, 1982, p.232). ${ }^{29}$

Outros autores retomaram essa noção de continuum, introduzida inicialmente por Macnamara (1966), que criou uma classificação em continuum com base nas quatro habilidades linguísticas: fala, compreensão auditiva, leitura e escrita. Esse espectro inclui diferentes tipos de indivíduos bilíngues. Teríamos então um continuum que iria de controle nativo a controle mínimo de uma das quatro habilidades linguísticas (MARCELINO, 2009, p. 5).

Mais recentemente, Li Wei (2000) publicou The Bilingualism Reader, onde apresenta um quadro com trinta e sete diferentes tipos de indivíduos bilíngues, com base na mesma noção de aquisição mencionada por Thiéry (1978): a aquisição simultânea - no caso em que o aprendizado das duas línguas ocorreu simultaneamente - e a consecutiva - no caso em que uma língua foi adquirida após a outra. Para Wei (2000), esta é a primeira pergunta que devemos responder antes de analisar o conhecimento e grau de fluência de uma pessoa numa determinada língua.

Em comum entre essas definições está o fato de que qualquer indivíduo que detenha algum conhecimento em uma segunda língua é classificado como bilíngue,

28 "Thus, our definition includes people ranging from the migrant worker who speaks with some difficulty the host country's language (and who cannot read and write it) all the way to the professional interpreter who is totally fluent in two languages."

29 "Bilingualism... may be of all degrees of accomplishment, but it is understood here to begin at the point where the speaker of one language can produce complete, meaningful utterances in the other language. From here it may proceed through all possible gradations up to the kind of skill that enables a person to pass as a native in more than one linguistic environment." 
independente do grau de fluência no idioma. Mas como essas visões podem ser aplicadas à situação peculiar do intérprete?

\section{3}

Tipos de bilinguismo na interpretação

Em primeiro lugar, é necessário definir o que entendemos por intérprete bilíngue. Utilizaremos as teorias apresentadas anteriormente para definir cada tipo de situação bilíngue. Adotaremos elementos de cada uma dessas duas visões, criando assim um continuum que se aplique exclusivamente à área da interpretação.

Num extremo desse continuum temos o intérprete que possui duas línguas $A$. Esse bilíngue seria o equivalente ao 'verdadeiro bilíngue' idealizado por Thiéry (1978). Os mais variados contextos podem dar origem a esse tipo de bilíngue. O caso mais comum é o do intérprete que reside num país bilíngue e cresce falando dois idiomas de maneira mais ou menos equivalente. Ou então o intérprete nascido de pais bilíngues cuja vivência permita que ambas as línguas sejam adquiridas e utilizadas a nível mais ou menos equivalente. Independente do contexto, esse tipo de intérprete é fruto de uma situação bastante peculiar e de acordo com Jones (2002) ocorre somente em casos excepcionais.

O segundo tipo de bilíngue é o intérprete que possui uma língua $A$ e pelo menos uma língua $B$ (podendo ter também línguas $C$ em sua combinação). Dependendo do contexto de trabalho, essas línguas B podem ser mais ou menos ativas; conforme vimos no primeiro capítulo, intérpretes do mercado institucional europeu tendem a trabalhar quase exclusivamente para a língua $A$, enquanto que 0 uso ativo da língua $B$ é bastante comum em mercados privados e fora da Europa Ocidental.

No outro extremo, temos o intérprete que trabalha com uma língua $A$, nenhuma língua $B$, e uma série de línguas $C$; essa é a classificação mais útil para intérpretes que desejam trabalhar em organismos internacionais. De acordo com a visão monolíngue ou parcial, esse intérprete não seria nem sequer considerado bilíngue. Mas pela visão de Macnamara (1966), ele faria parte do continuum pois é um intérprete que possui no mínimo um excelente controle em uma das quatro 
habilidades linguísticas: a compreensão auditiva. Esta compreensão é suficiente para a tarefa que desempenha.

Por estarem organizados nesse continuum, cada um desses tipos de bilíngues é usado como referência. Um intérprete com um controle quase nativo de uma língua $B$, por exemplo, estaria mais próximo do 'verdadeiro bilíngue' de Thiéry (1978). Na próxima seção, analisaremos o intérprete com duas línguas $A$.

\section{4}

\section{0 intérprete bilíngue}

Na área da interpretação, a definição normalmente associada à expressão "intérprete bilíngue" se refere àquele que declara ter duas línguas A em sua combinação. Ao longo desta seção explicaremos por que essa situação se produz somente em casos excepcionais e o que este tipo de combinação linguística implica.

Em primeiro lugar, esse tipo de intérprete deve estar ciente de que para cada uma de suas línguas $A$, deve possuir um domínio que atenda todas as competências específicas mencionadas no primeiro capítulo (seção 2.3). Competências como a capacidade de prever certas combinações de palavras num enunciado ou discernir entre sinônimos influirão diretamente na aceitação do indivíduo pela comunidade. Essa aceitação é o que faz do indivíduo um 'verdadeiro bilíngue'. No entanto, além de um conhecimento apurado da língua, o intérprete bilíngue se diferencia de outros bilíngues devido ao conhecimento exigido pela tarefa que desempenha.

O intérprete bilíngue deve ter cultura e conhecimento gerais equivalentes ao do nativo para cada uma de suas línguas $A$. Este conhecimento é o que dá ao profissional a capacidade de realmente "interpretar" a mensagem do orador. Para o ato da interpretação essas informações culturais são essenciais. Conforme TaylorBouladon (2007) nos lembra, a interpretação vai além da simples tradução literal:

"O intérprete é o mediador entre duas culturas, duas formas de ser. É uma criatura ambígua que pertence a dois mundos, que viveu aqui e lá, que faz parte de seu próprio povo mas é ao mesmo tempo um estrangeiro. Talvez ele seja mais parecido com um camaleão porque diz coisas diferentes dependendo da língua que estiver falando. Não são apenas as palavras, mas também os gestos, a expressão facial e 
até mesmo os maneirismos e comportamento que mudam de acordo com o idioma"(minha tradução, TAYLOR-BOULADON, 2007, p. 57). ${ }^{30}$

Esse tipo de conhecimento nato da cultura está fortemente associado a uma vivência no país. Tal vivência permite ao indivíduo com conhecimento linguístico adequado saber quando utilizar cada regra linguística de acordo com o contexto (GILE, 2007, p. 83).Isso faz com que o intérprete seja capaz de preencher as lacunas culturais e conceituais entre os participantes. Jones afirma que "pessoas de países diferentes podem não só falar línguas diferentes mas ter também um corpo de conhecimento diferente, educações diferentes, culturas diferentes e portanto uma abordagem intelectual diferente (minha tradução, JONES, 2002, p. 3)." ${ }^{31}$ Esta diferença é extremamente marcante durante atividades de versão, quando se traduz do português para o inglês. Apesar do intérprete que tem o português como língua nativa entender muito bem o que está sendo dito, a dificuldade é adaptar a abordagem intelectual brasileira, que tende a ser menos linear e metódica, à abordagem geralmente mais cartesiana dos falantes de inglês.

Apesar de ser um fenômeno raro, o intérprete bilíngue descrito acima de fato existe. No entanto, deve ter muita cautela ao classificar suas línguas de trabalho e optar por duas línguas A. Em alguns casos, este mesmo contexto pode também dar origem a uma situação extremamente peculiar onde um indivíduo detém um conhecimento em língua materna insuficiente para usá-la como língua $A$. Abordaremos esta situação no último capítulo.

\footnotetext{
30 "The interpreter is the mediator between two cultures, two ways of being. He is an ambiguous creature belonging to two worlds, who has lived here but also there, who is both part of his own people and a foreigner at the same time. [...][Perhaps, he is more like a chameleon because he says different things depending on the language he is speaking. It is not just the words, it is also the gesture, the facial expression and even the mannerisms and behaviour that change according to the language." 31 "People from different countries may not only speak different languages but have behind them different bodies of knowledge, different educations, different cultures, and therefore different intellectual approaches."
} 


\section{4 \\ INDÍVIDUO "SEM LÍNGUA"}

Opillard (2006) retoma o conceito de bilinguismo dividindo-o em diversos tipos. É de interesse para este trabalho entender a diferença entre o que o autor denomina 'bilinguismo coordenado' e 'bilinguismo composto' (OPILLARD, 2006, p.81). Esses dois tipos de bilinguismo são uma subdivisão do 'bilinguismo precoce', onde o aprendizado se dá por imersão. Conforme o autor argumenta, essa capacidade de aprendizado não mediado desaparece a partir de uma certa idade.

O bilinguismo coordenado é a situação em que a criança desenvolve dois sistemas linguísticos paralelos. Isso significa que para cada palavra, dispõe de dois significantes -a forma física de um signo ${ }^{32}$ - e dois significados - o sentido expresso por um signo ${ }^{33}$. A vantagem para esse tipo de bilíngue é que "para cada língua, os significados não serão praticamente nunca idênticos, não abrangerão totalmente os mesmos conceitos, as mesmas acepções, já que foram tomados de referências ambientais e valores ligados à cultura de origem" (minha tradução, OPILLARD, 2006, p.81). ${ }^{34}$

No bilinguismo composto, a criança desenvolve apenas um significado para dois significantes - um em cada língua - sendo incapaz de detectar diferenças conceituais entre os dois idiomas. O que se perde aqui é a sutileza de cada língua, o que leva à ausência de língua materna (OPILLARD, 2006, p.81).

É interessante observar que a situação do indivíduo "sem língua"35 tende a se manifestar em pessoas que são expostas desde cedo à várias línguas e culturas. Em seu blog ${ }^{36}$, Michelle Hof, intérprete de conferência profissional, professora e

\footnotetext{
${ }^{32}$ http://oxforddictionaries.com/definition/signifier?region=us\&q=signifier, acesso em 21/05/2012

$33 \mathrm{http}$ ://oxforddictionaries.com/definition/signified?region=us, acesso em 21/05/2012

34 "Dans chacune des langues, les signifiés ne seront pratiquement jamais identiques, ne recouvriront pas entièrement les mêmes concepts, les mêmes acceptions, car empreints de références environnementales et de valeurs liées à la culture d'origine".

35 Do inglês, "alingual".

${ }^{36}$ http://theinterpreterdiaries.com/2011/06/10/learning-your-abcs-the-interpreters-languages-parti/\#comments, acesso em 21/05/2012
} 
membro da AlIC, nos alerta para o fato de que há uma linha muito sutil entre um intérprete bilíngue - definido aqui como um intérprete com duas línguas $A$ - e o que ela chama de um indivíduo "sem língua". O termo se refere a alguém que não possui total domínio e fluência em qualquer língua (Chriss, 2006). Hof relata uma experiência em que um aluno de interpretação parecia ter um conhecimento perfeito de três idiomas. Durante o treinamento, foi ficando claro que o aluno não conseguia entender a diferença entres falsos cognatos e utilizava formulações que soariam estranhas para o nativo. Ela o caracterizou de "sem língua", porque não dominava nenhuma de suas línguas da mesma forma que um falante nativo dominaria a língua materna.

No caso de aluno mencionado acima, a situação pôde ser remediada a partir do momento em que este decidiu escolher uma de suas línguas $\mathrm{A}$ como dominante. Esta língua passou a ser a sua única língua $A$. Ao se concentrar em desenvolver apenas uma de suas línguas $\mathrm{A}$, o aluno foi capaz de levá-la ao nível exigido.

Esta situação nos alerta para o que pode acontecer caso não seja dada atenção suficiente à língua materna. O indivíduo 'sem língua' não é alguém cujo conhecimento seja insuficiente devido a uma educação falha. Pelo contrário, é fruto de um contexto extremamente peculiar em que a prevalência de uma língua sobre a outra nunca foi estabelecida. Este exemplo reforça a importância da língua materna para o intérprete. 


\section{5 \\ CONCLUSÃO}

Esta monografia buscou abordar a noção de língua materna, relacionando-a ao termo comumente associado na área da interpretação: língua $A$. O primeiro capítulo visou estabelecer uma estrutura teórica que explicasse como a nomenclatura da classificação linguística adotada internacionalmente é empregada. Buscou-se correlacionar diferentes teorias para estabelecer definições das línguas de trabalho, passando pelas competências linguísticas necessárias.

A partir das pesquisas, estabelecemos cinco competências linguísticas exigidas em língua A, com base nos achados de Carroll (1978). São elas:

- competência lexical;

- sensibilidade a certos usos do léxico e a nuances das expressões idiomáticas;

- capacidade de prever combinações lexicais num enunciado;

- reconhecimento de ambiguidade semântica e sintática;

- capacidade de expressar-se de maneira eficaz.

Com base nessas informações, os próximos capítulos exploraram duas situações extraordinárias de difícil classificação: a do intérprete bilíngue e a do indivíduo 'sem língua'. São situações de interesse também por se manifestarem em torno da língua materna. Para a primeira situação, chegou-se à conclusão de que a acepção mais comum do termo intérprete bilíngue dentro da área se refere àquele que possui duas línguas $A$, equivalente ao 'verdadeiro bilíngue' teorizado por Thiéry (1978). Apesar de excepcional, esta situação existe. É fruto, porém, de um contexto extremamente específico.

Revelou-se também que aspirantes a intérpretes que acreditam ter duas línguas $A$ devem ser extremamente cuidadosos quanto ao nível de domínio dessas línguas. Surpreendentemente, a situação do indivíduo 'sem língua', i.e., aquele cujo conhecimento em língua materna é insuficiente para se tornar intérprete profissional, resulta com mais frequência de uma situação de bilinguismo. Em alguns casos, 
como no exemplo explorado, é possível remediar tal situação estabelecendo a dominância consciente de uma língua sobre a outra.

Este trabalho pretendeu demonstrar o papel crucial da língua materna para o intérprete de conferências. Ao mesmo tempo em que o conhecimento das línguas estrangeiras é primordial para a interpretação, deve haver maior conscientização sobre a necessidade de se cultivar e aprimorar a língua materna. As instituições de ensino devem repassar aos alunos essa preocupação com a qualidade da língua materna através de cursos de aperfeiçoamento. No curso de formação de intérpretes de conferências da PUC, a matéria "Português para intérpretes" busca sanar dúvidas e erros comuns cometidos pelos alunos. É um excelente exemplo do tipo de iniciativa que deve estar integrada ao currículo das instituições de ensino.

O estudo foi limitado devido à falta de material empírico que corroborasse a questão. Poderíamos aprofundá-lo através de questionários destinados tanto a alunos de interpretação quanto a profissionais da área. Através da pesquisa, buscaríamos avaliar a importância atribuída por cada categoria à língua materna. Por outro lado, a questão do bilinguismo e sua relação com a interpretação merece aprofundamento por ser assunto de muito interesse para o ramo. Uma pesquisa poderia revelar se as percepções dos intérpretes no meio são compatíveis com a teoria exposta neste trabalho. 


\section{REFERÊNCIAIS BIBLIOGRÁFICAS:}

BRÄSCHER, Marisa. A Ambiguidade na Recuperação da Informação.

DataGramaZero - Revista de Ciência da Informação - volume 3, número 1, artigo 05. 2002. Disponível em www.dgz.org.br/fev02/Art 05.htm acesso em 03.05.2012. 24p.

BLOOMFIELD, Leonard. Language. Chicago: University of Chicago Press. 1984. 580p.

DONOVAN, Clare. Survey of Users - Expectations and Needs. EMCI Workshop: Teaching Simultaneous Interpretation into a "B" language vol. 1. 2002. Disponível em http://www.emcinterpreting.org/resources/simlntoB.php acesso em 23.02.2012. 68p.

FERREIRA, Aurélio Buarque de Hollanda. Novo Dicionário da Língua Portuguesa - Século XXI. Rio de Janeiro: Nova Fronteira, $2^{\mathrm{a}}$ Ed. 1993. 2128p.

GILE, Daniel. Basic Concepts and Models for Interpreter and Translator Training.Revisededition. Amsterdam/Philadelphia: Johns Benjamins PublishingCompany. 2009. 283p.

GROSJEAN, François. Life with two languages: An Introduction to Bilingualism. Cambridge, Massachussets: Harvard UniversityPress. 1982. 384p.

GROSJEAN, François. Individual Bilingualism. The Encyclopedia of Language and Linguistics.Oxford: PergamonPress. 1994. Disponível em http://www.loveandculture.net/Documents/26/individual bilingualism acesso em 26.01.2012.

GROSJEAN, François. Studying Bilinguals. Oxford: Oxford University Press. 2008. 352p.

HERBERT, Jean. The interpreter's handbook: how to become a conference interpreter. Genève: Librairie de L'Université. GEORG \& Cie S.A. 1952. 113p.

JONES, Roderick. Conference Interpreting Explained. 2nd edition.Manchester: St. JeromePublishing. 2002. 142 p.

MACNAMARA, John. The Bilingual's linguistic performance: a psychological overview. Journalof Social Issues 23: $59-77$, 
1966.Disponível em http://onlinelibrary.wiley.com/doi/10.1111/j.15404560.1967.tb00576.x/abstract acesso em 13.02.2012.

MARCELINO, Marcello. Bilinguismo no Brasil: significado e expectativas. Revista Intercâmbio, volume XIX. São Paulo: LAEL/PUCSP. 2009.

Disponível em

http://www4.pucsp.br/pos/lael/intercambio/revista intercambio volume \%20XIX.html acesso em 19.01.2012.

MINNS, Philip. Language Interpreting into B: Some Conclusion Gathered from Experience. B.EMCI Workshop: Teaching Simultaneous Interpretation into a "B" language - vol. 1. 2002. Disponível em http://www.emcinterpreting.org/resources/simlntoB.php acesso em 23.02.2012.68p.

OPILLARD, Thierry. Bilinguismes, compétences et outixinformatix. LesActes de Lecture, $n^{\circ} 94$, junho 2006. Disponível em www.lecture.org/ressources/.../page80.PDF acesso em 06.03.2012. 6p.

SZABARI, Krisztina. Interpreting into the B language.EMCI Workshop: Teaching Simultaneous Interpretation into a "B" language vol. 1. 2002. Disponível em http://www.emcinterpreting.org/resources/simlntoB.php acesso em 23.02.2012. 68p.

TAYLOR-BOULADON, Valerie. Conference Interpreting: Principles and Practice. 2nd edition. Rotterdam: Museum Boijmans Van Beuningen, 2007. 323p.

THIERY, Christopher. True bilingualism and second-language learning in Gerver, D. \&Sinaiko,H. (Eds.), Language, Interpretation and Communication. New York: PlenumPress. 1978. 145-153.

TYRUK, Malgorzata. Le perfectionnement linguistique pour les interprètes vers la langue $\mathrm{B}$.EMCI Workshop:

TeachingSimultaneousInterpretationinto a "B" language - vol. 1. 2002. Disponível em http://www.emcinterpreting.org/resources/simlntoB.php acesso em 23.02.2012. 68p.

WEI, Li. The Bilingualism Reader. London and New York: Routledge. 2000. Disponível em

http://books.google.com.br/books?id=GF7F XRozvAC\&printsec=frontco ver\&hl=pt-

BR\&source $=$ gbs ge summary $r \& c a d=0 \# v=$ onepage $\& q \& f=$ false acesso em 15.02.2012. 